\title{
Texture of the zona pellucida of the mature pig oocyte. The mammalian egg envelope revisited*
}

\author{
Jacques E. FLÉCHONa**, Vaclav KOPECNY ${ }^{\mathrm{a}}$, Juraj PIVKO ${ }^{\mathrm{b}}$, \\ Antonin PAVLOK ${ }^{\mathrm{c}}$, Jan MOTLIK ${ }^{\mathrm{c}}$ \\ a Biologie du Développement et Reproduction, INRA, 78352 Jouy-en-Josas, France \\ b Animal Production Research Institute, 94901 Nitra, Slovakia \\ ${ }^{c}$ Institute of Animal Physiology and Genetics, 27721 Libechov, Czech Republic
}

(Received 18 December 2003; accepted 17 February 2004)

\begin{abstract}
The zona pellucida (ZP) of mature pig oocytes is believed to consist of a dense filamentous meshwork, less compact on the inner and outer faces. The uneven surface of the ZP is made of unordered and stretched fibrils surrounding deep funnels which are the openings of the radial canaliculi. The topography of the ZP surface may contribute to the initial interplay between male and female gametes. Using cytochemical techniques for transmission electron microscopy (TEM), such as tannic acid and ruthenium red treatments, we found that the ZP of pig oocytes was essentially made of bundles of fibrils distributed in concentric layers (except in the innermost and outer parts). A correlation appears between the dense structure of the core layer of the ZP and its texture: it is constituted of superposed layers of fibril bundles, whereas only a random meshwork is found in a very thin innermost and in the outer layer. The fascicular configuration may control the permeability of the ZP, giving its semi-rigidity and elasticity, and may facilitate sperm penetration. The liquid crystal-like design of the core layer of the $\mathrm{ZP}$ is similar to textures found in the the vitelline envelope (zona radiata) of other vertebrates and possibly of all the deuterostomes. Such texture is probably related to the unique ZP protein composition and to a coordinated synthesis.
\end{abstract}

vitelline envelope / ultrastructural cytochemistry / glycoproteins / liquid crystal-like texture / Sus scrofa

\section{Abbreviations}

PVS: perivitelline space; SEM: scanning electron microscopy; TEM: transmission electron microscopy; ZP: zona pellucida.

\section{INTRODUCTION}

The oocytes of animals, including vertebrates, are surrounded as a rule by an enve- lope called either the vitelline envelope, the chorion, the zona radiata or the zona pellucida [1]. The thickness of the mammalian zona pellucida (ZP) is species-specific, e.g.

\footnotetext{
* Dedicated to Professor Charles Thibault

** Corresponding author: jb.flechon@ free.fr
} 
around $5 \mu \mathrm{m}$ in the mouse and around $10 \mu \mathrm{m}$ in the pig $[2,3]$; the multiple roles of the $\mathrm{ZP}$ have been thoroughly reviewed $[4,5]$. The site of ZP synthesis is the oocyte during its growth phase, at least in the mouse [6-8] and/or the follicular cells in other species $[3,9]$. A unifying hypothesis, at least on the composition of these envelopes, has been offered by molecular biology: the constitutive proteins are homologous and all belong to the ZP protein family [3, 10-12]. Does a common composition induce a similar structure of egg envelopes? The answer was readily given for several groups of vertebrates by electron microscope observations: in fishes and amphibians, e.g., the main part of the envelopes appear to be made of fibril bundles or sheets distributed in superposed layers $[1,13,14]$. Similar observations are lacking for mammals where "it would be of great interest... to compare the high-resolution structures of vitelline envelope and $\mathrm{ZP}$ glycoproteins" [15]. The aim of the present work was to obtain preliminary results on the ZP substructure of the pig as a model for mammals. We therefore used cytochemical techniques on maturing and ovulated oocytes of two different breeds. In all cases, the main part of the pig ZP appeared to be built of superposed layers of fibril bundles.

\section{MATERIALS AND METHODS}

\subsection{Collection of oocytes}

We used the same animals as in a previous work [16]. Ten prepubertal 5-6 month old gilts of miniature pigs (a cross-breed of Minnesota and Göttingen strains) were stimulated by $1000 \mathrm{IU}$ pregnant mare serum gonadotropin (PMSG) (Antex, Leo, Copenhagen) and $72 \mathrm{~h}$ later by $1500 \mathrm{IU}$ human chorionic gonadotropin (hCG) (Praedyn, Spofa, Prague) to obtain synchronized maturation. Injection of hCG represented time 0 for subsequent in vivo or in vitro meiotic maturation. Moreover, untreated cyclic gilts of the Large White breed were monitored daily for the onset of oestrus with a boar.
Unpenetrated oocytes were recovered by flushing the oviducts with phosphate buffered saline.

\subsection{In vitro maturation}

Oocyte-cumulus complexes (OCC) were mechanically isolated from excised ovaries of gilts at different times during treatment, after rupture of the follicular wall of the large preovulatory follicles. Some of the OCC were cultured in $0.1 \mathrm{~mL}$ of the following medium under paraffin oil at $38^{\circ} \mathrm{C}$ with $5 \% \mathrm{CO} 2$ in air: $18 \mathrm{~mL}$ of $1.45 \% \mathrm{NaHCO} 3$, $0.002 \%$ phenol red, $10 \mathrm{~mL}$ of $5.5 \%(\mathrm{w} / \mathrm{v})$ glucose solution, $4 \mathrm{mg}$ sodium pyruvate, $30 \mathrm{mg} \cdot \mathrm{mL}^{-1}$ freeze-dried calf serum growth proteins (Usol, Prague), 50 IU penicillin and $5 \mu \mathrm{g} \cdot \mathrm{mL}^{-1}$ streptomycin were added to $72 \mathrm{~mL}$ of isotonic TC 199 medium (Usol, Prague). During in vitro maturation, the oocytes had reached MI after one day of culture and were in MII after two days of culture.

\subsection{Electron microscope morphological and cytochemical studies}

Preparations for transmission electron microscopy (TEM) were made as described previously [16]. For the better preservation of glycoproteins and/or glycosaminoglycans, preovulatory oocytes, oocytes cultured in vitro and ovulated oocytes were treated during osmium tetroxide postfixation with $0.5 \%$ ruthenium red [17] or $1.0 \%$ tannic acid [18]. A series of ovulated oocytes were treated with $1 \%$ pronase (Calbiochem B grade) during 10 to $30 \mathrm{~min}$ at $38^{\circ} \mathrm{C}$ before fixation as above and ruthenium red treatment.

\section{RESULTS}

We call structure, the general architecture (overall morphology, compactness, transverse canaliculi) of the $\mathrm{ZP}$ and texture, its submicroscopic constitution (filamentous meshwork organization). 


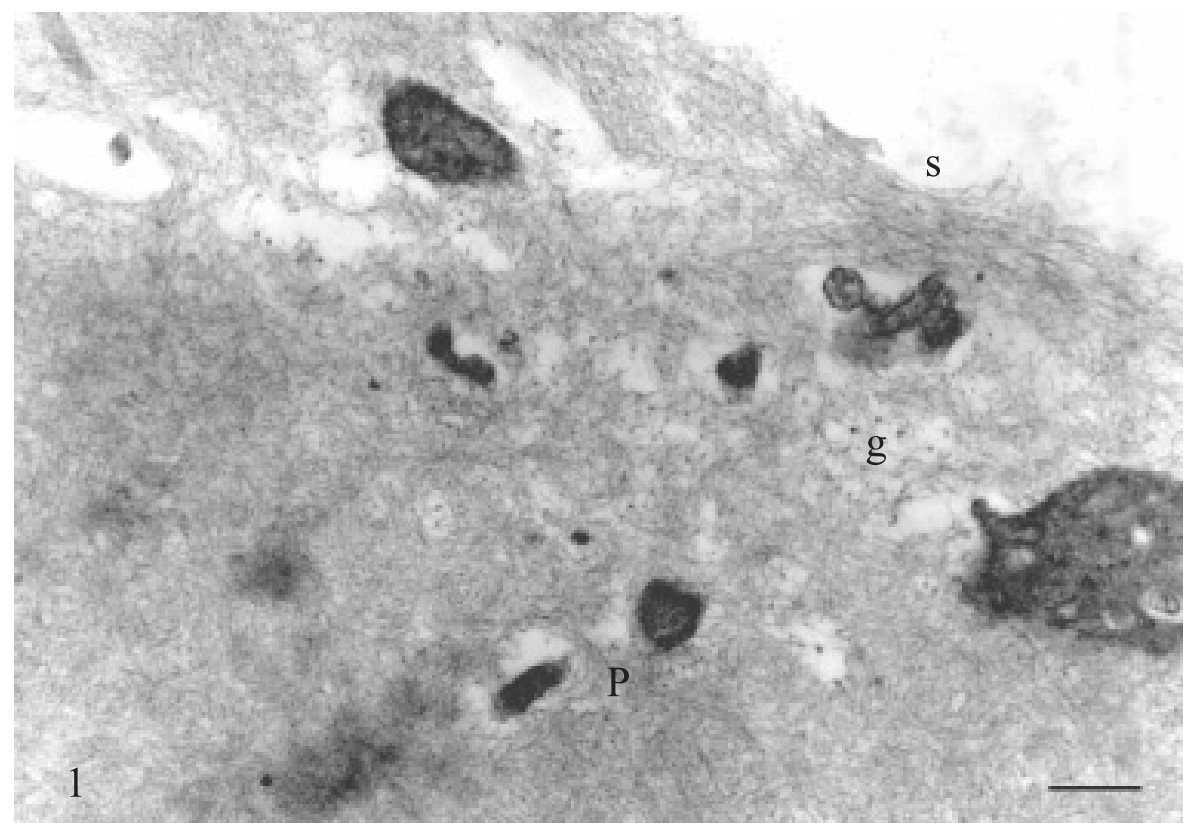

Figure 1. The outer part of the $\mathrm{ZP}$ of a pig oocyte collected $20 \mathrm{~h}$ after hCG and cultured in vitro until MII, shows a transition between inner fibril bundles and a porous surface (S) meshwork. Both layers are traversed by corona cell projections $(\mathrm{P})$. Granules $(\mathrm{g})$ contrasted by ruthenium red are found at the intersection of fibrils, mainly at the limit of the main and outer part of the ZP. Scale bar: $1 \mu \mathrm{m}$.

\subsection{Structure}

With standard techniques of TEM, the structure of the $\mathrm{ZP}$ of maturing and mature oocytes appeared as a dense fibrillar meshwork, less compact in the very thin inner and in the outer layer. The ZP was perforated by many funnel-like canaliculi containing cytoplasmic projections of the corona cells. When contrast was enhanced by use of tannic acid or ruthenium red, a fine random meshwork was visible in the outer (and a thin inner) layer of the ZP where electron dense granules were sometimes observed at fibril crossings (Fig. 1).

\subsection{Texture}

A different texture was observed in most of the thickness of the ZP: its fibrillar meshwork appeared not randomly arranged, but organized in closely apposed parallel bundles, themselves distributed in stratified layers (Figs. 1 and 2). A high magnification of the bundles is shown in Figure 3. Investigation on a limited number of samples showed that the diameter of the fibrils cut transversely varied from 6 to $14 \mathrm{~nm}$ after tannic acid or from 6 to $13 \mathrm{~nm}$ after ruthenium red treatment and the diameter of the bundles was 170 to $230-240 \mathrm{~nm}$ in both cases. The diameters were grouped around two values for fibrils, 6 and 9-12 nm and around $200 \mathrm{~nm}$ for the bundles. The distance from the centre to the centre of the bundles in a row was approximately $250 \mathrm{~nm}$, which means that the bundles may be separated by a small space.

The bundle arrangement was observed in the ZP during in vitro maturation, after both full in vivo or in vitro maturation of miniature pig oocytes, and also in ovulated 

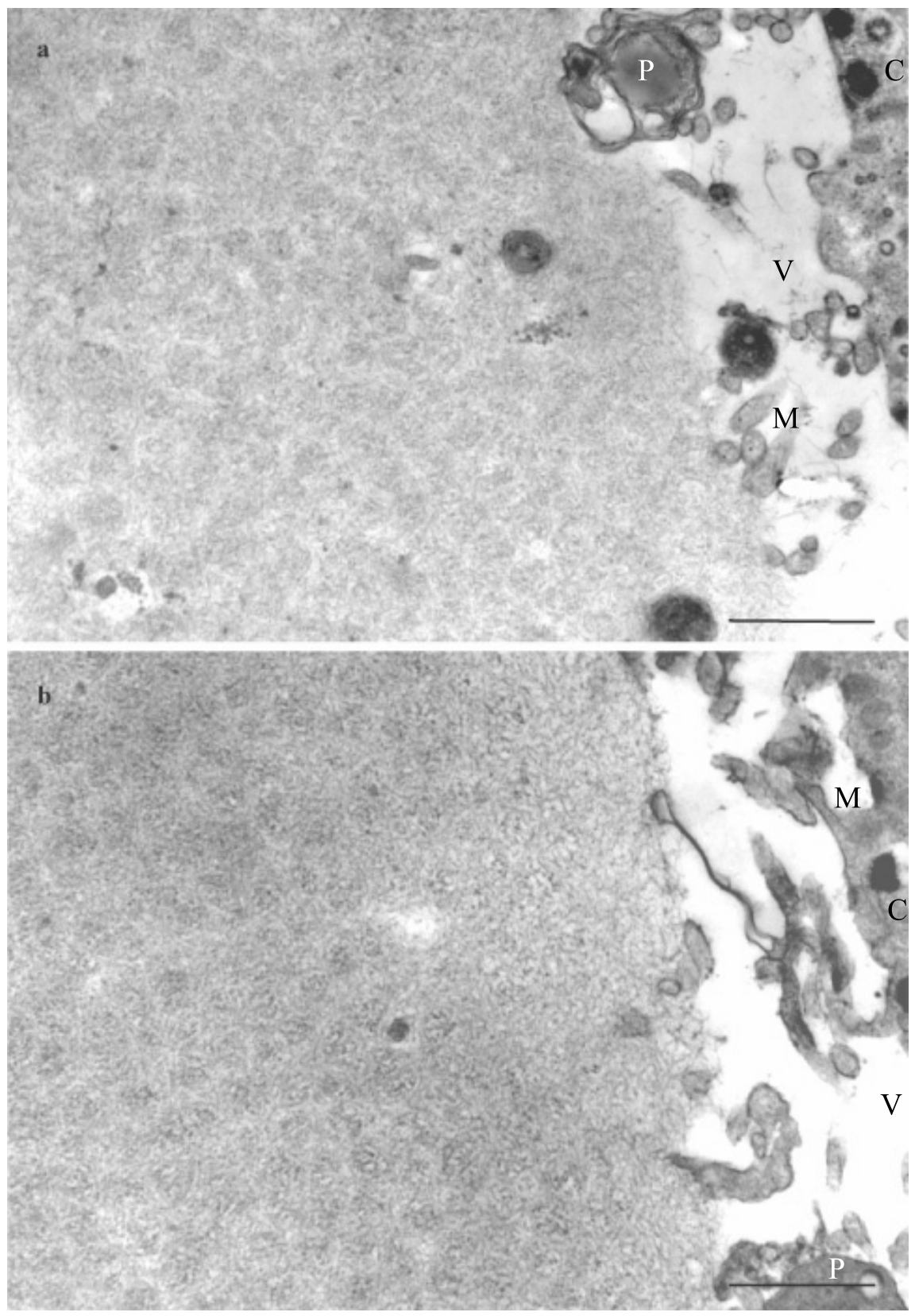

Figure 2. TEM of the ZP (central and inner part) of pig oocytes after tannic acid (a) and ruthenium red treatment (b). (a) Oocyte collected $20 \mathrm{~h}$ after hCG and cultured until MII. (b) Oocyte entirely matured in vitro. In both cases the ZP appears to be made of bundles of fine fibrils oriented parallel in cross section. Such regular texture is progressively less defined towards the inner face. Cytoplasmic structures in the PVS are corona cell projections (P) and oocyte microvilli (M). Cortical granules (C) are visible under the oolemma. Scale bar: $1 \mu \mathrm{m}$. 


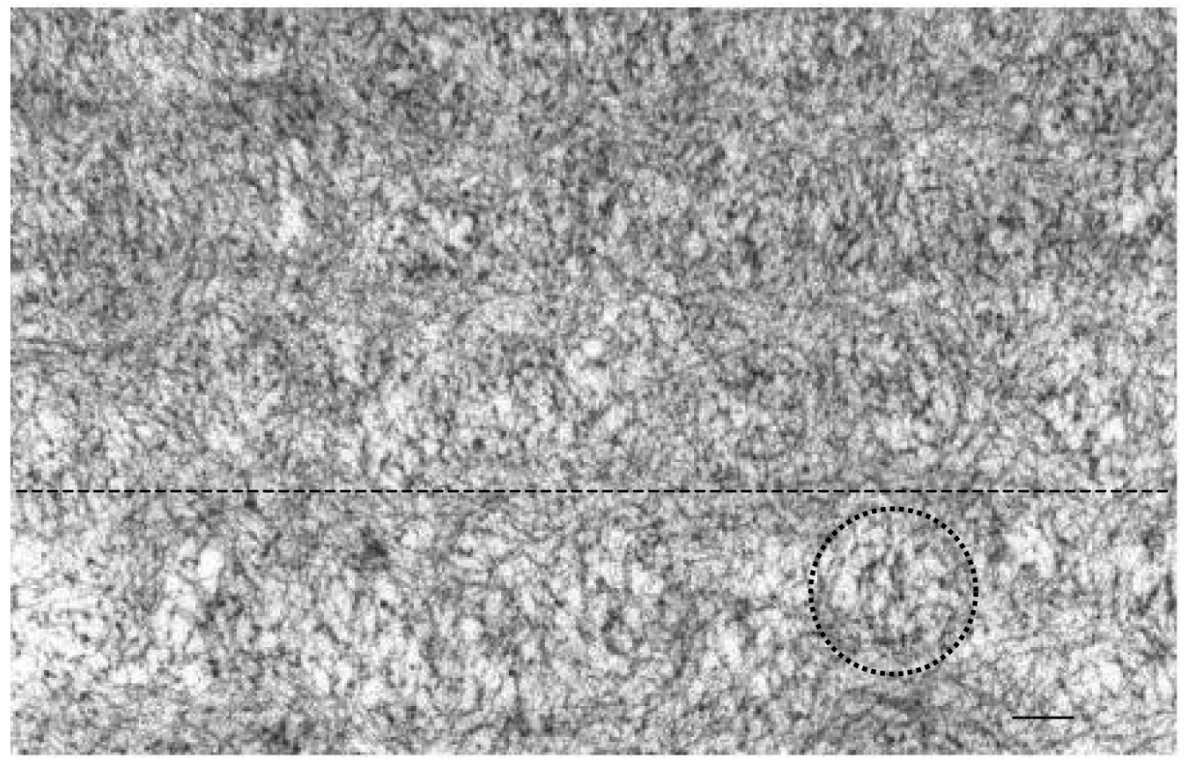

Figure 3. High magnification of a portion of the main part of the $\mathrm{ZP}$ of an oocyte matured in vitro until MII after ruthenium red treatment. The over-contrasted view shows the profile of the parallel fibril bundles in cross section. The contour of one bundle and the limit between two bundle layers were marked. Scale bar: $0.1 \mu \mathrm{m}$.

oocytes of the Large White breed. Such texture was even more evident when the $\mathrm{ZP}$ was partially digested by pronase in conditions giving complete lysis in around $30 \mathrm{~min}$; in this case, the bundles appeared separated from each other before being digested (Fig. 4). A scheme representing the distribution of the parallel fibril bundles in superposed layers is given in Figure 5.

\section{DISCUSSION}

We will focus the discussion on the similarity of texture between the main part of the pig egg envelope and that of other vertebrates. In a second part of the discussion, we will analyse the relationship between texture and chemical composition and evaluate the implications of the dual texture of the $\mathrm{ZP}$ on its functions at the time of fertilization.

\subsection{ZP Structure and texture}

\subsubsection{Structure}

After in vivo or in vitro maturation, the $\mathrm{ZP}$ of pig oocytes showed the same structure as that observed in other eutherians, that is a dense fibrillar meshwork, becoming less compact on both faces or at least on the outer face [19-22]. The ZP is perforated by radial canaliculi containing the cytoplasmic processes of the corona cells and contacting the surface of the immature oocyte [23]. It should be stressed that these corona cell expansions are not at any time actively penetrating the $\mathrm{ZP}$; the latter is built around these processes as well as around the short oocyte microvilli [24].

The trans-zona corona cell expansions form crater-like openings on the ZP surface, as illustrated by SEM observations of mature 


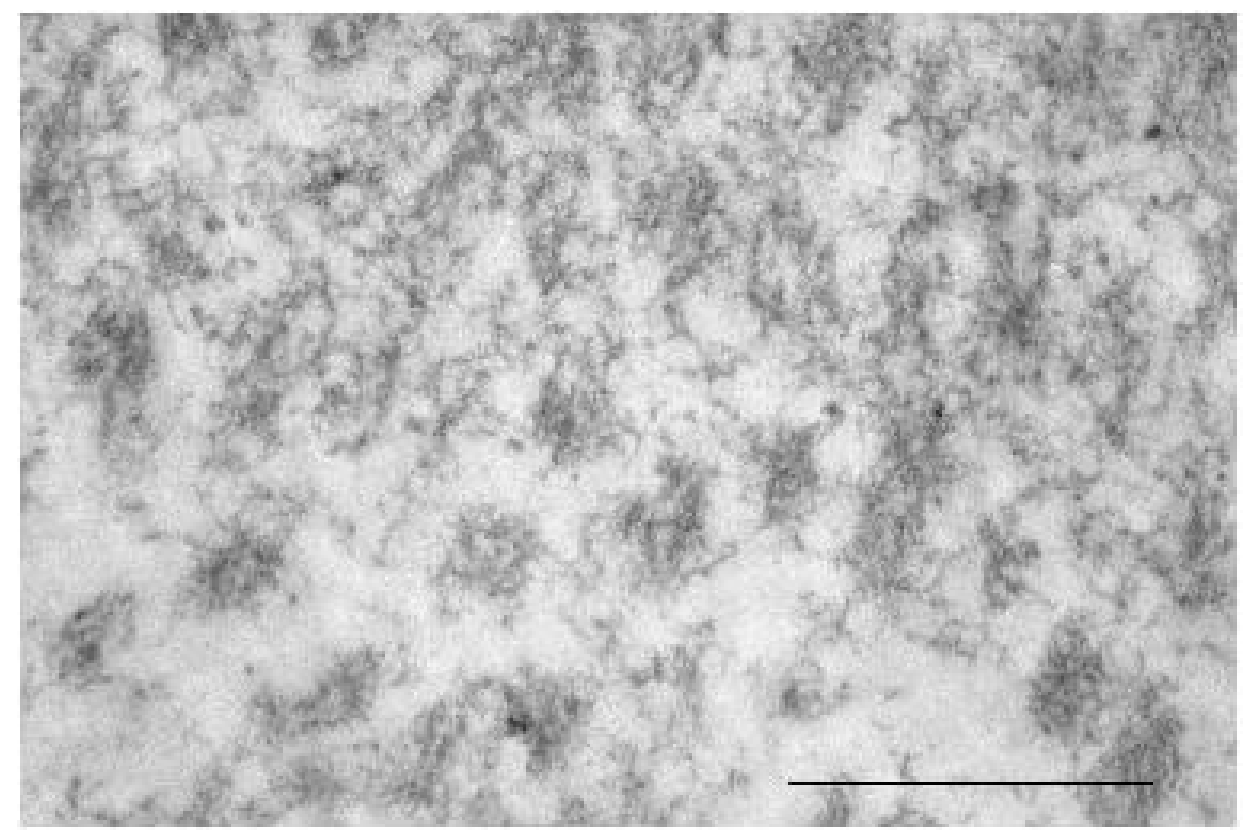

Figure 4. Progressive -from outside (bottom-left) to inside (top-right)-dissociation and lysis of the fibril bundles in the main part of the ZP of an ovulated oocyte after treatment with $1 \%$ pronase $\left(25 \mathrm{~min}\right.$ at $38^{\circ} \mathrm{C}$ ) before fixation and ruthenium red treatment. Scale bar: $1 \mu \mathrm{m}$.

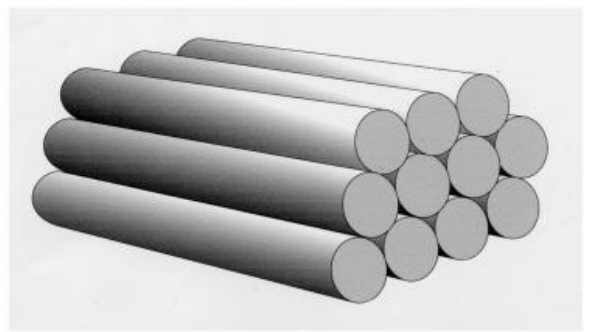

Figure 5. Scheme of a few stratified layers of parallel fibril bundles in the core layer of the ZP. On a short length, the bundles appear parallel and rectilinear. The eventual small space between the bundles is neglected.

pig oocytes [25] and of oocytes of other species $[26,27]$. A porous outer surface was also observed on the ZP of marsupial oocytes [28].

\subsubsection{Texture}

Following tannic acid and ruthenium red treatments, the observed diameter of the pig ZP fibrils (6 to $12 \mathrm{~nm}$ ) was comparable to the dimensions of rat fibrils (4-7 nm) contrasted with tannic acid [29] and to extracted mouse fibrils, looking like "beads on a string", whose beads measured about $9 \mathrm{~nm}$ in diameter [22]. With both techniques, the two more frequent diameters observed for fibrils may correspond to the beads and the strings.

After use of ruthenium red, we occasionally observed granules at the fibril intersections in the superficial meshwork of the $\mathrm{ZP}$ which looked like the granules described at the onset of ZP deposition between the follicular cells and the oocyte [24]. They probably represent accumulations of the contrasting agents [26] rather than the structures of unknown nature described throughout the rabbit [30] and pig ZP [24]. 
Tannic acid and ruthenium red treatments showed that the core layer of the ZP was built of bundles of fibrils oriented in strata parallel to the oocyte surface. This corresponds to a cholesteric liquid crystallike state found in many biological systems [31].The diameter of the bundles and their alinement were not rigorously uniform, organic structures being subject to variations and defects even present in the mineral crystals. How is it possible to interpret the distribution of bundles in three dimensions? The bundles may be arranged like the threads in a wool ball, forming with each other angles too small to be appreciated on a transverse section. The texture of fibril bundles did not change during maturation, all the more if the latter was incomplete in vitro, as we found it identical after ovulation. The formation of the ZP is probably achieved at the final stage of oocyte growth [32] and it is readily penetrable by sperm in germinal vesicle oocytes [33]. Although alterations in ZP thickness have been reported after ovulation [20], our results show that, if true, they do not affect the fasciculated configuration. However, changes in bundle association (compaction) were observed in the vitelline envelope of Xenopus, after ovulation [34], and modifications may also occur particularly in the outer layer. Differences in pig ZP between oocytes matured in vitro or in vivo may be attributed to an incomplete maturation in the first case and/ or to extracellular matrix addition in the second case [20,35].

The fascicular configuration of pig $\mathrm{ZP}$ was the same in miniature pigs and in the Large White breed. It was not an artefact due to in vitro maturation or to the treatment by tannic acid or ruthenium red, since we observed the same texture after in vivo maturation, even without the use of tannic acid or ruthenium red. However the contrast was very low in the latter case.

Superposed sheets or bundles of fibrils were observed in teleost inner zona radiata [36, 37], in Xenopus laevis [14] and Discoglossus pictus [13] egg envelopes. More- over, in echinoderms, the oocyte envelope also looks threaded like a tennis ball framework [38]. So it is suggested that the egg vestment has evolved in the deuterostome phylum from a common model, which must be correlated with the coordinate deposition of its components [21, 39]. If the texture of pig $\mathrm{ZP}$ is similar to that of various vertebrates, it may be taken as a plausible model for other eutheriens.

The uniformity of $Z P$ texture in vertebrates can be explained by a common composition actually limited to a few glycosylated proteins, such as in the pig [21]. These glycoproteins all belong to the ZP family and generally contain a common domain or " $\mathrm{ZP}$ module" [9]. There are three single-copy $\mathrm{ZP}$ genes in mammals ZPA, ZPB, ZPC [3] including marsupials [11]. Depending on the species, ZPA in the mouse [40] or ZPB in the pig [3, 41] would constitute sperm receptors. More generally, it appears that all egg envelope glycoproteins of vertebrates belong to the same family $[10,12,21,42]$.

In the mouse, the non covalently bound proteins $\mathrm{ZP} 2$ and $\mathrm{ZP} 3$ form filamentous polymers cross-linked by the third protein ZP1 [8]. Such macromolecular complexes may well give rise to the fibril bundles we observed. The ZP proteins are sensitive to proteases (including acrosin) inducing specific cleavages in $\mathrm{ZP}$ proteins, but not complete lysis, [9], to disulphide-bond cleaving agents and low $\mathrm{pH}$ (inducing changes in glycoprotein conformation, but not disruption of covalent bonds [43]). The use of pronase (in the present work) may explain the unveiling of the pig ZP texture by separating the fibril bundles. Solubilization with $\mathrm{Li}-$ 3,5 di-iodosalicylate of pig ovarian oocytes resulted in the complete separation of the fibrils on the ZP surface and in the disclosure of fibril bundles in the interior [19]. The authors have overlooked the meaning of their observations which is presently revealed. Conversely we suspect that destabilization with saponin before fixation may disorganize the native texture of the ZP [20,26]. Nevertheless "areas of major condensation", 
probably bundles, are revealed this way in the $\mathrm{ZP}$ core layer of in vitro fertilized human ova [26].

\subsection{Is the $\mathrm{ZP}$ texture correlated to its local chemical composition?}

Our results show that the outer (and the thin inner) part of the ZP are not only less compact than the core layer as already known, but that they also have a different physical texture. Are the pig ZP layers of different chemical composition and/or cellular origin? Several, non exclusive either physical or chemical explanations can be given to the heterogeneity of the ZP.

The zona radiata of fishes shows several layers of different texture corresponding to the successive steps of deposition [1]. In a teleost, "the amorphous material of the inner zona radiata is secreted by the oocyte and assembles in a filament which then forms part of a highly ordered... layer" [37]. Similarly, the mode of deposition of the mammalian ZP proteins may differ from the onset to the end; the ZP first appears as disconnected patches of a fuzzy meshwork between the oocyte and follicle cells [24]. When becoming continuous, the ZP may gain a more regular texture. Moreover, at the end of the process, the first deposited and now peripheral meshwork may be stretched and/or disrupted during the increase of ZP thickness. On the inner side of the ZP, the building of bundles may be interrupted when the ZP protein synthesis is declining.

The texture heterogeneity may explain a difference in layer permeability, responsible for a pseudo chemical heterogeneity. Effectively, although the ZP is permeable to a large spectrum of components [23, 44], differential staining of the ZP layers was obtained by treatment en bloc of the oocytes with antibodies or lectins $[19,45,46]$. The diffusion of (immuno)cytochemical reactions must be easy in the spongy outer layer; it may be progressively hampered while the $\mathrm{ZP}$ is becoming a plugged filter or when reagents precipitate in the periphery $[47$,
48]. The radial canaliculi would not play any role in permeability if they are effectively closed after corona projections withdrawal. In vivo contamination of the $\mathrm{ZP}$ surfaces by the extracellular matrix during maturation $[16,44,49]$ may also alter stainability [50].

The polymorphism of $\mathrm{ZP}$ proteins can result from many post-transcriptional modifications including Asn-(N-) and Ser/Thr(O-) glycosylation and addition of disulphide-bonds and sialic acid groups [15]. The staining of ovarian sections with lectins for sugar distribution revealed heterogeneities in the ZP (layers of different affinities) of eutherians [50, 51] and marsupials [52]. So glycosylation may change, particularly at the onset and/or the end of ZP secretion, inducing stronger lectin binding in the outer and/or inner faces of the ZP.

Immunochemistry on thin sections using antibodies to $\mathrm{ZP} 1, \mathrm{ZP} 2, \mathrm{ZP} 3$ revealed a homogeneous protein distribution in the $\mathrm{ZP}$ of mouse ovarian oocytes, although local densities may correspond to fibril aggregates (bundles?) [6]. However, in other species, changes may occur in ZP protein gene expression during the course of synthesis and/or according to the site of synthesis, that is corona cells versus oocytes [3]. In pigs, although a contribution to ZP3 by follicular cells has been reported [53], transcripts of ZP1 were found only in growing oocytes [54], and no labeling was observed at the TEM level in follicular cells using three monoclonal antibodies to ZP proteins [55].

In clonclusion, the model of mammalian $\mathrm{ZP}$ we propose has at least two layers of different texture probably responsible for unequal permeability and contamination by secretions of the oocyte and of the cumulus oophorus. ZP heterogeneities may just result from the order of synthesis or from mechanical effects during deposition. Moreover they may also be due to a different chemical composition (changes in ZP proteins or in glycolysation). 


\subsection{Physiological properties of the $\mathrm{Zp}$ in mature oocytes inferred by its texture}

\subsubsection{Surface}

The chaotic structure of the surface, and particularly the craters, when made empty by the loss of corona cells which begin to disperse $3 \mathrm{~h}$ after ovulation in the pig, may eventually be mechanical traps where spermatozoa start to penetrate the ZP tangentially (Fig. 2 in [56]). In this species, the supernumerary heads remain trapped almost parallel to the surface of the $\mathrm{ZP}$ in its non compacted easier to penetrate outer part [57]. SEM observations also indicate that sperm heads initiate penetration parallel to the surface of the hamster ZP [58, 59] and that the physical properties of the outer surface of the ZP may be important for human sperm adhesion [60]. An extreme case of physical interaction between mammalian gametes is given by a shrew, the sperm of which appears to bind to the ZP after the acrosomal reaction by barbs of the perforatorium [61]. Anyway, adhesion to- and onset of penetration of the $\mathrm{ZP}$ would probably be less easy if its surface was flat and smooth. The physical interactions between the sperm and ZP surface could be redundant with the elusive ligand-receptor system [62]. Both phenomena may explain why sperm do not bind efficiently to the inner face of the ZP when externalized [45, 63]. So the surface of the ZP appears to be functionally adapted by different means including its structure to sperm binding.

\subsubsection{Core layer}

The mechanical properties of the $\mathrm{ZP}$ were previously compared to those of a sulfated glycoprotein gel [21]. In fact, the texture of the main part of the ZP, made of several layers of fibril bundles (like a tire armature), can explain the well known envelope resistance and elasticity useful for micromanipulation.
The generally oblique (parabolic?) "penetration curve", is observed in the ZP of several species including the pig $[64,65]$; it may result from the sliding of the flat and asymmetrical (spoon-like or hook-like) acrosome-reacted sperm head, due to a hyperactive movement of the flagellum [66], through the parallel fibril bundles. If the penetration is purely mechanical [67], the insinuation of the sperm head between the bundles may just slightly distort the compact material of the core layer in eutherians [68] as well as in marsupials [28]. Contribution of acrosomal enzymes remains to be clearly demonstrated. In didelphid marsupials however, the thin protease sensitive $\mathrm{ZP}$ would allow its perforation by acrosomal enzymes [67]. In teleost oocytes, it is well known that sperm penetrates via the micropyle [1]; in this case, the layers of fibril bundles are oriented at different angles as in plywood, a type of texture that would inhibit sperm edging; in mammals, the fibril bundles would be almost parallel, as discussed above. So in vertebrates, sperm penetration could depend on the physico-chemical and substructure variants of the vitelline envelope, although at least its main part has a common constitution of ZP proteins forming superposed fibril layers or bundles. In this context, unveiling the texture of the $\mathrm{ZP}$ in other mammalian species, particularly in those where sperm penetration is atypical, will be rewarding. It will also be interesting to consider how important the ZP texture is on the "zona reaction" after fertilization and on zona permeability, distension and shedding during early development.

\section{CONCLUSION}

Besides the known uniformity of composition, the present demonstration that the texture of the main part of a mammalian $\mathrm{ZP}$ is not an exception among that of vertebrates, is a new confirmation that "Vertebrate egg envelopes... are basically similar" [1]. It appears that the composition and substructure of the egg envelopes of vertebrates are very 
well adapted to their functions, since they appear to have evolved little even after the divergence of the tetrapodes from fishes.

\section{ACKNOWLEDGMENTS}

This work was partly supported by the Grant Agency of the Czech Republic. Best thanks to J. Degrouard for preparing the plates, to C. Thibault, H. Funahashi and J.M. Bedford for constructive reading of the manuscript and to G. Seidel for revising the style.

\section{REFERENCES}

[1] Dumont JN, Brummett AR. Egg envelopes in Vertebrates. In: Browder LW (Ed), Developmental Biology, A comprehensive synthesis, Plenum Press, New York 1985, p 235-288.

[2] Dunbar BS, Wardrip NJ, Hedrick JL. Isolation, physicochemical properties and macromolecular composition of zona pellucida from porcine oocytes. Biochemistry 1980, 19: 356365.

[3] Sinowatz F, Töpfer-Petersen E, Kölle S, Palma G. Functional morphology of the zona pellucida. Anat Histol Embryol 2001, 30: 257-263.

[4] Herrler A, Beier HM. Early embryonic coats: morphology, function, practical applications. Cells Tissues Organs 2000, 16: 233-246.

[5] Wassarman PM, Jovine L, Litscher ES. A profile of fertilization in mammals. Nature Cell Biol 2001, 3: 59-64.

[6] El-Mestrah M, Castle PE, Borossa G. Kan FWK. Subcellular distribution of ZP1, ZP2, ZP3 glycoproteins during folliculogenesis and demonstration of their topographical disposition the zona matrix of mouse ovarian oocytes. Biol Reprod 2002, 66: 866-876.

[7] Fléchon JE, Pavlok A, Kopecny V. Dynamics of zona pellucida formation by the mouse oocyte. An autoradiographic study. Biol Cell 1984, 51: 403-406.

[8] Wassarman PM, Liu C, Litscher ES. Constructing the mammalian egg zona pellucida: some new pieces of an old puzzle. J Cell Sci 1996, 109: 2001-2004.

[9] Prasad SV, Skinner SM, Carino C, Wang N, Cartwright J, Dunbar BS. Structure and function of the proteins of the mammalian Zona pellucida. Cells Tissues Organs 2000, 166: $148-164$.

[10] Lindsay LL, Wallace MA, Hedrick JL. A hatching enzyme substrate in the Xenopus laevis egg envelope is a high molecular weight ZPA homolog. Dev Growth Differ 2001, 43: 305-313.

[11] Selwood L. Marsupial egg and embryo coats. Cells Tissues Organs 2000, 166: 208-219.

[12] Vaccaro MC, De Santo MG, Caputo M, Just M, Tian JD, Gong H, Lennarz WJ, Campanella C. Primary structure and developmental expression of Dp ZP2, a vitelline envelope glycoprotein homolog of mouse ZP2, in Discoglossus pictus, one of the oldest living anuran species. Mol Reprod Dev 2001, 59: $133-143$.

[13] Caputo M, Infante V, Talevi R, Vaccaro MC, Carotenuto R, Campanella C. Following passage through the oviduct, the coelomic envelope of Discoglossus pictus (Amphibia) acquires fertilizability upon reorganisation, conversion of gp 42 to gp 40, extensive glycosylation, and formation of a specific layer. Mol Reprod Dev 2001, 58: 318-329.

[14] Larabell CA, Chandler DE. The coelomic envelope of Xenopus laevis eggs: a quickfreeze, deep-Etch analysis. Dev Biol 1989, 131: 126-135.

[15] Wassarman PM. Mammalian fertilization: molecular aspect of gamete adhesion exocytosis, and fusion. Cell 1999, 96: 175-183.

[16] Fléchon JE, Degrouard J, Kopecny V, Pivko J, Pavlok A, Motlik J. The extracellular matrix of porcine mature oocytes: origin, composition and presumptive roles. Reprod Biol Endocr 2003, (I) 1: 124.

[17] Luft JH. Ruthenium red and violet. I Chemistry, purification, methods of use for electron microscopy and mechanism of action. Anat Rec 1971, 171: 347-368.

[18] Singley CT, Solursh M. The use of tannic acid for the ultrastructural visualization of hyaluronic acid. Histochemistry 1980, 65: 93-102.

[19] Dietl J, Czuppon AB. Ultrastructureal studies of the porcine zona pellucida during the solubilization process by Li-3,5-diiodosalicylate. Gamete Res 1984, 9: 45-54.

[20] Funahashi H, Ekwall H, Kikuchi K, RodriguezMartinez H. Transmission electron microscopy studies of the zona reaction in pig oocytes fertilized in vivo and in vitro. Reproduction 2001, 122: 443-452. 
[21] Green PL. Three-dimensional structure of the zona pellucida. Rev Reprod 1997, 2: 147-156.

[22] Greve JM, Wassarman PM. Mouse egg extracellular coat is a matrix of interconnected filaments possessing a structural repeat. J Mol Biol 1985, 181: 253-264.

[23] Vanroose G, Haunwynck H, Van Soom A, Ysebaert MT, Charlier G, Van Oostveldt P, de Kruif A. Structural aspects of the zona pellucida of in vitro-produced bovine embryos: a scanning electron and confocal laser scanning microscopic study. Biol. Reprod. 2000, 62: 463-469.

[24] Dietl J. Ultrastructural aspects of the developing mammalian zona pellucida. In: Dietl $\mathbf{J}$. (Ed), The Mammalian Egg Coat: Structure and Function, Springer Verlag, Berlin 1989, p 49-60.

[25] Fléchon JE, Motlik J, Hunter RHF, Fléchon B, Fulka J. Cumulus oophorus mucification during resumption of meiosis in the pig. A scanning electron microscope study. Reprod Nutr Dev 1986, 26: 989-998.

[26] Familiari G, Nottola SA, Macchiarelli G, Micara G, Aragona C, Motta PM. Human zona pellucida during in vitro fertilization: an ultrastructural study using saponin, ruthenium red, and osmium-thiocarbohydrazide. Mol Reprod Dev 1992, 32: 51-61.

[27] Phillips DM, Shalgi R. Surface architecture of the mouse and hamster zona pellucida and oocyte. J Ultrastruct Res 1980, 72: 1-12.

[28] Breed WG. Egg maturation and fertilization in marsupials. Reprod Fertil Dev 1996, 8 (1996) 617-643.

[29] Takeuchi IK, Takeuchi YK. Use of tannic acid for ultrastructural visualization of zonae pellucidae in growing oocytes of rat ovarian follicles. Zool Sci 1985, 2: 135-139.

[30] Pedersen H, Seidel G Jr. Micropapillae: A local modification of the cell surface observed in rabbit oocytes and adjacent follicular cells. J Ultrastruct Res 1972, 39: 540-548.

[31] Bouligand Y, Denefle JP, Lechaire JP, Maillard M. Twisted architectures in cell-free assembled collagen gels: study on collagen substrates used for cultures. Biol Cell 1985, 54: 143-162.

[32] Yoshida M, Cran DG, Pursell VG. Confocal and fluorescence microscopic study using lectins on the distribution of cortical granules during the maturation and fertilization of pig oocytes. Mol Reprod Dev 1993, 36: 462-468.
[33] Overstreet JW, Bedford JM. Comparison of the permeability of the egg vestments in follicular oocytes, unfertilized and fertilized ova of the rabbit. Dev Biol 1974, 41: 185-192.

[34] Grey RD, Working PK, Hedrick JL. Alteration of structure and penetrability of the vitelline envelope after passage of eggs from coelom to oviduct in Xenopus laevis. J Exp Zool 1977, 201: 73-84.

[35] Wang WH, Abeydeera LR, Prather RS, Day BN. Morphologic comparison of ovulated and in vitro-matured porcine oocytes, with particular reference to polyspermy after in vitro fertilization. Mol Reprod Dev 1998, 49: 308-316.

[36] Corporiccio B, Connes R. Étude ultrastructurale des enveloppes périovocytaires et périovulaires de Dicentrotus Labrax L. (Poisson téléostéen). Ann Sci Nat Zool (Paris) 1977. 19: 351-368.

[37] Wourms JB. Annual fish oogenesis. I. Differentiation of the mature oocyte and formation of the primary envelope. Dev Biol 1976, 50: $338-354$.

[38] Chandler DE, Kazilek CJ. Extracellular coats on the surface of Strongylocentrotus purpuratus eggs: stereo electron microscopy of quickfrozen and deep-etched specimens. Cell Tissue Res 1986, 246: 153-161.

[39] Epifano O, Liang LF, Familari M, Moos MC Jr, Dean J. Coordinate expression of the three zona pellucida genes during mouse oogenesis. Development 1995, 121: 1947-1956.

[40] Talbot F, Shur BD, Myles D. Cell adhesion and fertilization: steps in oocyte transport, sperm-zona pellucida interactions and spermegg fusion. Biol Reprod 2003, 68: 1-9.

[41] Miller DJ, Burkin HR. Gamete adhesion molecules. Reproduction 2001, Suppl 58: $147-$ 158.

[42] Voyle RB, Haines BP, Loffler KA, Hope RM, Rathjen PD, Breed WG. Isolation and characterisation of zona pellucida A (ZPA) cDNAs from two species of marsupial: regulated oocyte-specific expression of ZPA transcripts. Zygote 1999, 7: 239-248.

[43] Inoue M, Wolf DP. Solubility properties of the murine zona pellucida. Biol Reprod 1974, 10: 512-518.

[44] Suzuki H, Jeong BS, Yang X. Dynamic changes of cumulus-oocyte cell communication during in vitro maturation of porcine oocytes. Biol Reprod 2000, 63: 723-729. 
[45] Ahuja KK, Bolwell GP. Probable asymmetry in the organization of components of the hamster zona pellucida. J Reprod Fertil 1983, 69: 49-55.

[46] Nicolson GL, Yanagimachi R, Yanagimachi H. Ultrastructural localization of lectin-binding sites on the zonae pellucidae and plasma membranes of mammalian eggs. J Cell Biol 1975, 66: 263-27.

[47] Dudkiewicz AB, Shivers CA, Williams WA. Ultrastructure of the hamster zona pellucida treated with zona precipitating antibody. Biol Reprod 1976, 14: 175-185.

[48] Sacco AG, Yurewicz EC, Subramanian MG, Matzat PD. Porcine zona pellucida: association of sperm receptor activity with the $\alpha$ - glycoprotein component of the $\mathrm{Mr}=55000$ family. Biol Reprod 1989, 41: 523-532.

[49] Talbot F, Dicarlantonio G. The oocyte-cumulus complex: ultrastructure of the extracellular components in hamster and mice. Gamete Res 1984, 10: 127-142.

[50] Avilés M, Okinaga T, Shur BD, Ballesta J. Differential expression of glycoside residues in the mammalian zona pellucida. Mol Reprod Dev 2000, 57: 296-308.

[51] El-Mestrah M, Kan FWK. Distribution of lectin-binding glycosidic residues in the hamster follicular oocytes and their modifications in the zona pellucida after ovulation. Mol Reprod Dev 2001, 60: 517-534.

[52] Chapman JA, Wiebkin OW, Breed WG. Interspecific variations of zona pellucida glycoconjugates in several species of marsupial. J Reprod Fertil 2000, 119: 111-120.

[53] Sinowatz F, Amselgruber W, Topfer-Petersen E, Totzaner I, Calvete J, Plendl J. Immunocytochemical characterization of porcine zona pellucida during follicular development. Anat Embryol 1995, 191: 41-46.

[54] Taya T, Yamasaki N, Tsubamoto H, Hasegawa A, Koyama K. Cloning of a cDNA coding for porcine zona pellucida glycoprotein $\mathrm{ZP1}$ and its genomic organization. Biochem Biophys Res Comm 1995, 207: 790-799.

[55] Takagi J, Dobashi M, Araki Y, Imai Y, Hiroi M, Tonosaki A, Sendo F. The development of porcine zona pellucida using monoclonal antibodies. II. Electron microscopy. Biol Reprod 1989, 40: 1103-1108.

[56] Fléchon JE. Acrosome reaction, sperm penetration and gamete fusion in Mammals. In:
Mohri H. (Ed), New Horizons in Sperm Cell Research, Japan Science Society Press, Tokyo and Gordon and Breach Science Publ, New York 1987, p 235-246.

[57] Thibault C. Analyse de la fécondation de l'œuf de la truie après accouplement ou insémination artificielle. Ann Zootech 1959, Suppl 165-177.

[58] Gwatkin RBL, Patterson H. Association of mammalian sperm with the cumulus cells and the zona pellucida studied by scanning electron microscopy. Scanning Electron Microscopy IITRI 1976, Part VI, p 379-384.

[59] Yanagimachi R, Phillips DM. The status of acrosomal caps of hamster spermatozoa immediately before fertilization in vivo. Gamete Res 1984, 9: 1-19.

[60] Familiari G, Nottola SA, Micara G, Aragona C, Motta PM. Is the sperm-binding capability of the zona pellucida linked to its surface structure? A scanning electron microscopic study of human in vitro fertilization. J In vitro Fertil Embryo Transfer 1988, 5: 134-143.

[61] Kaneko T, Iida H, Bedford JM, Mori T. Spermatozoa of the shrew, Suncus Murinus, undergo the acrosome reaction and then selectively kill cells in penetrating the cumulus oophorus. Biol Reprod 2001, 65: 544-553.

[62] Castle PE. Could multiple low-affinity bonds mediate primary sperm-zona pellucida binding? Reproduction 2002, 124: 29-32.

[63] Phillips DM, Shalgi R. Surface properties of the zona pellucida. J Exp Zool 1980, 213: 1-18.

[64] Dziuk PJ, Dickmann Z. Sperm penetration through the zona pellucida of the sheep egg. J Exp Zool 1965, 158: 237-239.

[65] Yanagimachi R. Mammalian fertilization. In: Knobil E, Neill J.D. (Eds), The Physiology of Reproduction. Raven Press, New York 1994, p 189-317.

[66] Yanagimachi R. Time and process of sperm penetration into hamster ova in vivo and in vitro. J Reprod Fertil 1966, 11: 359-370.

[67] Bedford JM. Mammalian fertilization misread? Sperm penetration of the eutherian zona pellucida is unlikely to be a lytic event. Biol Reprod 1998, 59: 1275-1287.

[68] Huang TTF, Yanagimachi R. Inner acrosomal membrane of mammalian spermatozoa: its properties and possible functions in fertilization. Am J Anat 1985, 174: 249-268. 